Pre-Print Manuscript:

Bridgelall, R., and Stubbing, E. (2020). Forecasting the Effects of Autonomous Vehicles on Land Use. Technological Forecasting and Social Change, DOI: 10.1016/j.techfore.2020.120444.

1 FORECASTING THE EFFECTS OF AUTONOMOUS VEHICLES ON LAND USE

3 Raj Bridgelall (Corresponding Author)

4 Assistant Professor of Transportation and Program Director

5 Department of Transportation, Logistics, and Finance, North Dakota State University

$6 \quad$ P.O. Box 863676, Plano, TX 75086

7 Phone: (408) 607-3214; Email: raj@bridgelall.com

8 ORCID: 0000-0003-3743-6652

9

10 Edward Stubbing

11 Senior Transportation Planner

12 Rail \& Transit, Transportation, AECOM

13 201-45 Goderich Road, Hamilton, ON, L8E 4W8, Canada

14 Phone: (905) 755-8958; Email: edward.stubbing@ aecom.com

15 ORCID: 0000-0003-1346-6865

16

Conflict of Interest: The authors declare that they have no conflict of interest.

\begin{abstract}
The widespread availability of connected and autonomous vehicles (CAVs) will likely affect social change in terms of how people travel. Traditional methods of travel demand and land use modeling require vast amounts of data that could be expensive to obtain. Such models use complex software that requires trained professionals to configure and hours to run a single scenario. Alternative closedform models that can quickly assess trends in potential CAV impact on the regional demand for shopping, entertainment, or dining land use does not exist. This research developed a closed-form model that considers the potential mode shift towards CAVs, possible changes in the propensity to travel, shopping trip avoidance from e-commerce, and greater accessibility for non-drivers. Model parameter estimation based on statistics from the greater Toronto area found that population growth from 2017 to 2050 alone could increase the demand for shopping, entertainment, or dining land use by nearly $60 \%$. However, CAVs could double or triple that demand-implicating dynamic planning and environmental considerations.
\end{abstract}

Keywords: Environmental impact; Intelligent transportation systems; Self-Driving Cars; Travel Demand; Transportation technology; Urban sprawl 


\section{FORECASTING THE EFFECTS OF AUTONOMOUS VEHICLES ON LAND USE}

\section{INTRODUCTION}

The deployment of connected and autonomous vehicles (CAVs), also known as self-driving vehicles, will fundamentally affect travel demand and, consequently, land-use. Nevertheless, there is high uncertainty about the level of potential impact (Calvert, et al., 2018). Meanwhile, retailers are blurring the lines between shopping, entertainment, and dining (SED) land use as they shift towards experiential retail (Henderson \& Spencer, 2016). This trend will sustain the use of cars for longer non-stop trips to suburban SED centers or mixed-use areas (Anderson, et al., 2014). Subsequently, there is a need to understand how CAVs will affect the demand for SED space to inform planning.

There are few comprehensive reviews of international modeling studies on the impacts of CAVs on travel behavior and land use. None examine the influence of CAVs on the demand for SED land use (Soteropoulos, et al., 2019). Although the rise of e-commerce could prevent some of those trips, research suggest that online shopping is associated with higher in-store shopping (Lee, et al., 2017). Hence, many retailers are adding an online alternative to their traditional physical stores (Melis, et al., 2015).

The objective of this paper is to develop a closed-form model that can estimate the incremental influence that CAVs could have on the demand for SED or mixed-use space in the future. Model parameter estimation will use data available for the GTA so that the model can simulate demand sensitivity in the horizon year by sweeping factors that CAV adoption could influence. The authors selected the GTA because of familiarity with the area and knowledge of data sources that are unique to the region. The available trip survey data classified trips taken for SED purposes as discretionary trips to differentiate them from trips taken between home and work, home and school, and for non-home-based trips. The model focuses on technology adoption with the view that producers will pursue market growth, thus assuring ample supply.

The development of most models to estimate CAV impacts on travel behavior and land-use involve complex and expensive software, large datasets, and trained professionals. The results are very sensitive to model assumptions (Soteropoulos, et al., 2019). The long time taken to run a single scenario makes it impractical to conduct demand sensitivity analyses for a wide range of parameter values. Furthermore, the data-driven nature of trip-based, activity-based, and agent-based models makes it difficult to gain insights about how various factors of adoption interact over time (Soteropoulos, et al., 2019).

The main contribution of this paper is a closed-form model that would allow users to quickly examine a range of scenarios to see patterns over time and gain insights. The model will complement data-driven models that are more complex by providing an aggregate first-order picture of the travel demand sensitivity to variations in factors that CAVs could influence. Potential users of the model are urban planners, transport planners, the commercial real estate industry, and the retail or service industries. The results will implicate dynamic policy considerations.

The organization of the rest of this paper is-Section 2 reviews the literature on CAV adoption forecasting. Section 3 describes the sub-models used to develop the final closed-form model. Section 4 describes the model parameters, the values used to estimate them, and the data sources. Section 5 evaluates the model to obtain trends and horizon year sensitivity to adoption parameters. Section 6 discusses the findings, utility of the model, and limitations of the work. Section 7 provides some concluding remarks about the findings, generalizations of the method, and comments on future work. 


\section{LITERATURE REVIEW}

The subsections of this literature review cover existing knowledge about all the main concepts used to develop the model. They include land use, the propensity to travel, attracting new transportation users, and models to forecast adoption and population growth.

\subsection{Land Use}

There have been some speculations in the literature about projected changes in land use for SED purposes in urban and suburban areas. The reduced need for CAV parking can stimulate developers to repurpose urban parking spaces (Wang, et al., 2014). SED land use in those areas will likely decline to accommodate more pedestrian-friendly and mixed-use areas (Banai \& Antipova, 2016). However, large-format retailers will continue to seek cost reductions and access to more affordable employees by developing centralized spaces outside of the urban center. For instance, large-format retailers are planning to build more stores in the greater Toronto area (GTA), which is Canada's largest metropolitan market (Webber \& Hernandez, 2016).

\subsection{Propensity to Travel}

Travel demand is a non-linear and psychological function of cost and other factors (Lam \& Liu, 2017). Habit and satisfying behaviors are also factors (Lyons, 2006). Traveling for SED purposes is one of the most expensive and time-consuming activities in any affluent society (Maat \& Konings, 2018). Cost is a dominant factor in the propensity to travel for discretionary purposes (Arabani \& Amani, 2007). Factors driving the reduction of vehicle operating costs include driver cost elimination, lower insurance fees, less frequent maintenance, and lower fuel costs (Bösch, et al., 2018). Analysts speculate that insurance cost will diminish if the CAV accident rate decreases (Dedon, et al., 2018). Furthermore, vehicle electrification will reduce refueling costs (Kempton, 2016). Essential trips tend to be price inelastic but discretionary trips are sensitive to price changes (Oum, et al., 1990). Shopping trips are both essential and non-essential. Many trips are also multipurpose (Arentze, et al., 2005). An analysis of ride-sharing data from Uber found that a $10 \%$ increase in price is associated with a 10\% decrease in ridership (Cohen, et al., 2016). These evidences suggest that the propensity to travel for SED purposes would increase if CAVs decrease travel cost and increase the value of travel time.

\subsection{New Users}

There is general agreement that CAV fleets will increase accessibility for non-drivers such as the young, elderly, and disabled (Sivak \& Schoettle, 2015). The convenience of on-demand door-to-door service, privacy, the freedom to use travel time as desired, smoother traffic flows, and more efficient route selection could influence a mode shift away from passenger trains and buses (Bagloee, et al., 2016). Shorter travel time and competitive pricing for shared mobility services will increase the propensity to travel longer distances in cars, rather than using public transit services (Zhao \& Kockelman, 2018). There is evidence that more adults are using mobility-on-demand services to provide trips for their elderly parents and young children (Tussyadiah, et al., 2017). These statistics and trends suggest that future CAV fleets can fulfill a growing demand from new users. 


\section{$1 \quad 2.4 \quad$ Adoption Forecast}

2 Predictions of CAV deployment timing varies widely. From 2014 to 2017, technology companies, 3 vehicle manufacturers, and startup companies around the world have invested more than $\$ 80$ billion 4 to develop self-driving vehicles (Hussain, et al., 2018). A highly cited study predicts that CAVs will 5 account for $40 \%$ of all vehicle travel by 2040 (Litman, 2017). A case study of Austin, Texas, suggests that an annual price drop of 5\% and a constant willingness-to-pay (WTP) could result in a 24.8\% penetration of CAVs by 2045 (Bansal \& Kockelman, 2017). The level of penetration would increase substantially if price drops further and WTP values increase. The high external costs of traffic accidents and urban congestion caused a plateauing of personal vehicle ownership in Canada (Shenstone-Harris, 2016). This evidence suggests that future travel in Canada will shift from private cars and transit to shared CAVs.

The most popular model of technology adoption forecasting is a logistic growth model (Rogers Everett, 2003). It is an s-shaped curve that is based on the established theory of technology diffusion. Diffusion theory speculates that adoption comes in five stages. Innovators $(2.5 \%)$ are the first adopters. Early adopters (13.5\%), early majority (34\%), late majority (34\%), and then laggards $(16 \%)$ follow. This work uses a classical population growth model that uses an exponential curve (Pollard, 1973).

\section{METHODS}

This section develops the closed-form model as a function of time. Figure 1 shows the model architecture.

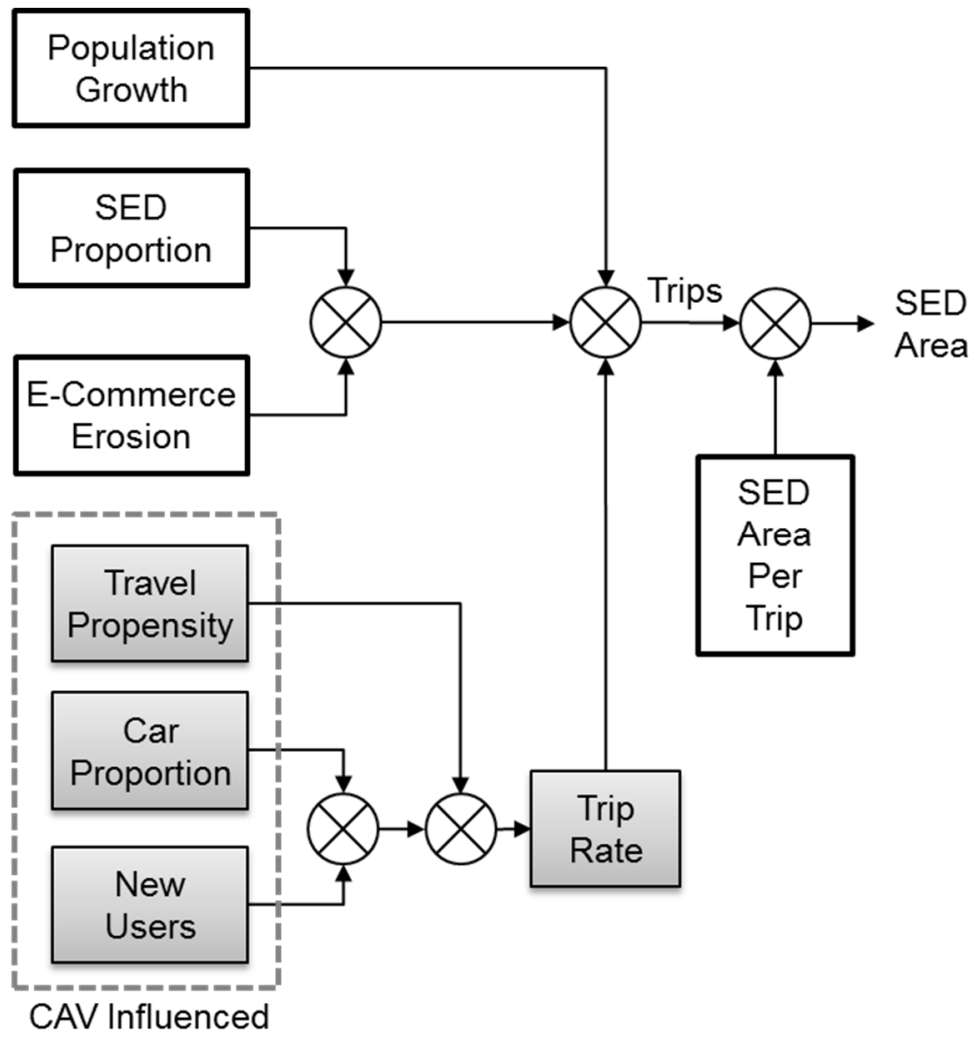

Figure 1. Model architecture and variables influenced by CAV adoption. 
1 The logic flow shows that six key parameters account for trip production for SED purposes. The parameters not influenced by CAV adoption are population growth, the proportion of trips taken for SED purposes, and a correction factor for trips done by e-commerce instead. The parameters influenced by CAV adoption are travel propensity, car proportion, and new users. Estimation of the model parameters is based on statistics for GTA population growth, the non-driver proportion, trip rate, travel mode, and the proportion of trips that are discretionary. The change in propensity to travel based on CAV adoption directly modulates the daily average trip rate per person for trips taken by car. Hence, the model design establishes the daily average trip rate per person and the proportion of cars used for discretionary trips as variables to enable demand sensitivity analysis.

\subsection{Trip Production}

The Ontario Ministry of Finance projected that the GTA population will grow from 6.9 million in 2017 to 9.7 million by 2041 (MOF, 2018). This growth is equivalent to an annual growth rate of $1.43 \%$. As introduced in the literature review, this work uses a classic compounded population growth model where

$$
P\left(y, \alpha_{\mathrm{p}}\right)=P_{0}\left(1+\alpha_{\mathrm{p}}\right)^{(y-y 0)}
$$

The parameter $\alpha_{\mathrm{p}}$ is the annual growth rate, $y$ is the year variable, and $y 0$ is the base year. The same

$$
\lambda_{\mathrm{c}}\left(y, \varepsilon_{\mathrm{p}}\right)=\lambda_{\mathrm{T}}\left(1+\varepsilon_{\mathrm{p}}\right)^{(y-y 0)}
$$

where a low value for the annual percentage growth, $\varepsilon_{\mathrm{p}}$, produces the appearance of a linear relationship with time. The parameter $\lambda_{\mathrm{T}}$ is the trip rate of the base year in average trips per person. This model accounts for the potential elasticity in trip production per capita for discretionary trips to SED areas. A range of values for $\varepsilon_{\mathrm{p}}$ can simulate scenarios for trip rate changes based on changes in the propensity to travel.

Equation (3) is logistic model that captures the proportional increase in mobility for new users, the non-driver population, that can use CAVs in future year $y$ based on an adoption rate $k_{\mathrm{n}}$ such that

$$
\rho_{\mathrm{N}}\left(y, k_{\mathrm{n}}\right)=\frac{\rho_{\mathrm{N} 0}}{1+e^{-k_{n}\left(y-y_{m}\right)}}
$$

The parameter $y_{\mathrm{m}}$ is the middle year between the horizon and base years. Figure 1 illustrates the difference between the exponential and logistic growth curves. 


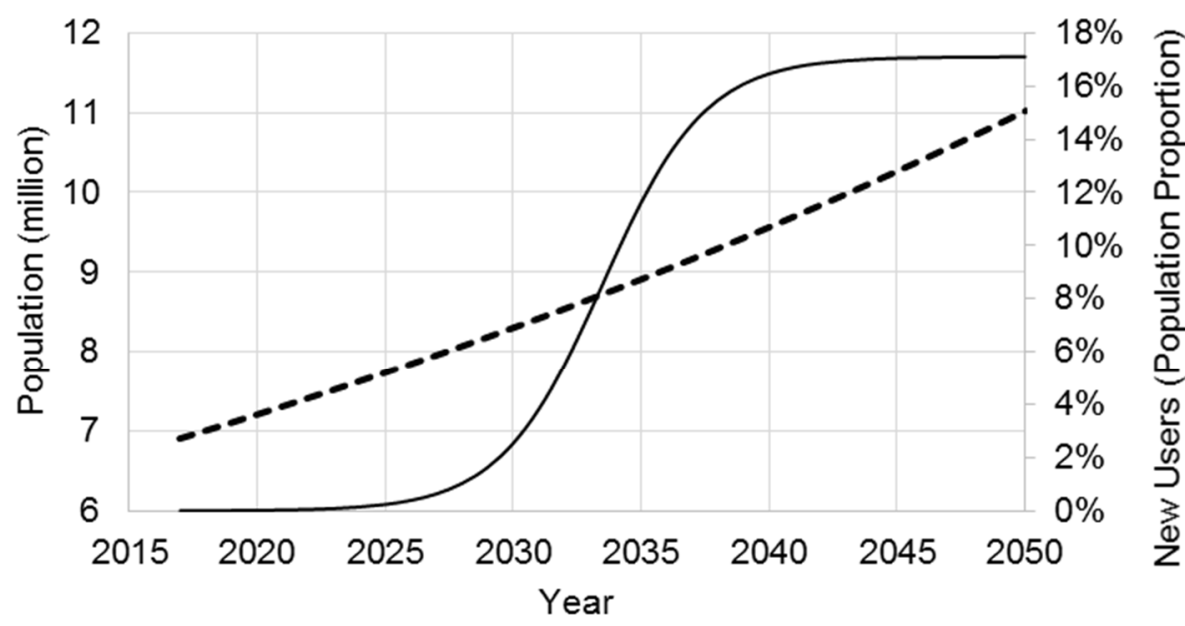

---Population — New Users

The parameter $\rho_{\mathrm{c}}$ is proportion of trips by cars. Trips taken by alternative modes is

$$
T_{\mathrm{a}}\left(y, \varepsilon_{\mathrm{p}}, \rho_{\mathrm{c}}\right)=\lambda_{\mathrm{T}} P\left(y, \alpha_{\mathrm{p}}\right)\left[1-\rho_{\mathrm{c}}\right]
$$

11 Alternative modes are vehicles that are not cars, such as buses, bicycles, walking, and trains. For

Forecasts in the literature for a given year can provide an estimate for the adoption rate parameter. A Canadian study found that, based on disabilities alone, approximately $17 \%$ of the population is nondrivers (Statistics Canada, 2019). The plot shows a scenario where less than $5 \%$ of the non-driver population becomes new users of CAVs by 2030 , and by 2050 , the full $17 \%$ of the population will become new users.

The number of trips by CAVs is

$$
T_{\mathrm{C}}\left(y, \varepsilon_{\mathrm{p}}, \rho_{\mathrm{c}}\right)=\lambda_{\mathrm{c}}\left(y, \varepsilon_{\mathrm{p}}\right) P\left(y, \alpha_{\mathrm{p}}\right)\left[1+\rho_{\mathrm{N}}(y)\right] \rho_{\mathrm{c}}
$$
alternative modes, this model uses the trip rate for the base year to simulate the fact that the rate remained constant from 1986 to 2011 and that it will likely remain inelastic for future discretionary trips by non-CAV modes.

\subsection{E-commerce Factor}

The rise of e-commerce will erode trips made for shopping but not necessarily all discretionary trips such as those made for dining and entertainment. The model accounts for this erosion by adjusting the trip rate as

$$
T_{\mathrm{ts}}\left(y, \varepsilon_{\mathrm{p}}, \rho_{\mathrm{c}}\right)=T_{\mathrm{t}}\left(y, \varepsilon_{\mathrm{p}}, \rho_{\mathrm{c}}\right)\left[1-\rho_{\mathrm{e}}\right] \rho_{\mathrm{s}}
$$

The function $T_{\mathrm{t}}$ is the total trips by cars and alternative modes, $\rho_{\mathrm{s}}$ is the proportion of trips made for shopping, and $\rho_{\mathrm{e}}$ is the proportion of those trips that e-commerce erodes. The s-curve models the increase in on-line shopping to a saturation point in the future such that

Figure 2. Population growth and the non-driver population proportion adoption CAVs.

$$
\rho_{\mathrm{e}}\left(y, k_{\mathrm{e}}\right)=\rho_{0 \mathrm{~s}}+\frac{\Delta \rho_{0 s}}{1+e^{-k_{e}\left(y-y_{m}\right)}}
$$


where $\rho_{0 \mathrm{~s}}$ is the proportion of shopping trips that e-commerce erodes in the base year and $\Delta \rho_{0 \mathrm{~s}}$ is the difference in the erosion at the horizon year. The parameter $k_{\mathrm{e}}$ accounts for a rate of change in shopping trip erosion from e-commerce during the peak adoption years.

\subsection{Propensity to Travel}

The literature review suggests that a shift away from vehicle ownership and towards mobility-ondemand services will further reduce travel costs. Consequently, the propensity to travel for discretionary trips will increase. GTA travelers took most of their discretionary trips by car. The trip proportion, as either a driver or a passenger ranged from 74\% in 1986 to $78 \%$ in 2011 (TT2012, 2012). Those trips were by personal vehicles because ride sharing was still in development. The dominant factors in vehicle operating cost are purchase price, fuel, insurance, maintenance, tires, oil, and licensing fees. The base-year estimate does not include parking costs because private owners tend to park in their driveways, on the street, or in the free parking lots of shopping, dining, or entertainment facilities. The cost does not include tolls because in the GTA, the main freeway (Highway 401) is toll-free at the time of this writing. However, without knowing how future costs will influence changes in future trip rates, the strategy was to use trip rate as a variable in the model to enable demand sensitivity analysis.

\subsection{Land Use}

There are many measures of SED business viability. Among them are sales per unit area of land use, gross margin, walk-in rate, and foot traffic (Daamen, et al., 2005). The latter two are directly proportional to the number of trips taken for SED purposes. Hence, this metric must be directly proportional to the number of SED trips per unit area of land use. Therefore, this model uses the number of trips made for SED purposes per unit of the land area used for SED in the GTA as a minimum threshold to meet future demand. Subsequently, the demand for future SED land use area is

$$
A_{\mathrm{s}}\left(y, \varepsilon_{\mathrm{p}}, \rho_{\mathrm{c}}\right)=\frac{A_{\mathrm{r} 0}}{T_{\mathrm{t} 0}} T_{\mathrm{ts}}\left(y, \varepsilon_{\mathrm{p}}, \rho_{\mathrm{c}}\right)
$$

The parameters $A_{\mathrm{r} 0}$ and $T_{\mathrm{t} 0}$ are the land area and the number of SED trips made in the base year. The 28 complete model for SED land use demand as a function of future year $y$ is

$$
\begin{gathered}
A_{\mathrm{s}}\left(y, \varepsilon_{\mathrm{p}}, \rho_{\mathrm{c}}\right)=\frac{A_{\mathrm{r} 0}}{T_{\mathrm{t} 0}} \times P_{0}\left(1+\alpha_{\mathrm{p}}\right)^{(y-y 0)} \times \\
{\left[\lambda_{\mathrm{T}}\left(1+\varepsilon_{\mathrm{p}}\right)^{(y-y 0)}\left(1+\frac{\rho_{\mathrm{N} 0}}{1+e^{-k_{n}\left(y-y_{m}\right)}}\right) \rho_{\mathrm{c}}+\lambda_{\mathrm{T}}\left(1-\rho_{\mathrm{c}}\right)\right] \times} \\
{\left[1-\rho_{0 \mathrm{~s}}-\frac{\Delta \rho_{0 s}}{1+e^{-k_{e}\left(y-y_{m}\right)}}\right] \rho_{\mathrm{s}}}
\end{gathered}
$$

The full model expresses the three main factors in SED land use demand, which are population growth, trip production based on the CAV effect, and an adjustment from the effect of e-commerce. The second factor expresses the CAV influence on the propensity to travel, the increase in accessibility for non-drivers, and the potential change in the proportion of discretionary trips made by cars. 
This general model form supports the simulation of other trip types such as home-basedwork (HB-W), home-based-school (HB-S), and non-home-based (N-HB) trips by replacing $\lambda_{T}$, the average daily trip rate in the base year (trips/person) for those trip purposes, and $\rho_{c}$, the percentage of cars used for those purposes. Similarly, the model can account separately for the different types of discretionary trips by estimating those parameters with data for a local region.

\section{DATA}

8 The data needed to evaluate the model for the GTA is not available in scholarly articles. Hence, this section uses data from available Canadian sources such as government reports, the websites of research organizations, and survey results from market research firms. Table 1 summarizes the model parameters, their values, the year that the value was measured, and the data sources.

3 Table 1. Model parameters, values, and data sources.

\begin{tabular}{llrrl}
\hline Var & Description & Value & Year & Data Source \\
\hline$y 0$ & Analysis base year & 2017 & 2017 & - \\
$y \mathrm{H}$ & Analysis horizon year & 2050 & - & - \\
$P_{0}$ & Population in base year (million) & 6.9 & 2017 & (MOF, 2018) \\
$\alpha_{\mathrm{p}}$ & Population annual growth rate (\%) & 1.43 & 2017 & Calculated \\
$\rho_{\mathrm{s}}$ & Proportion of trips that were discretionary (\%) & 0.41 & 2011 & (TT2012, 2012) \\
$\rho_{\mathrm{c}}$ & Proportion of all trips by car (\%) & 78 & 2011 & (TT2012, 2012) \\
$\lambda_{\mathrm{T}}$ & Average daily trip rate in the base year (trips/person) & 2.4 & 2011 & (TT2012, 2012) \\
$\mathrm{T}_{\mathrm{t} 0}$ & Trips made for shopping in 2006 (billion) & 2.25 & 2006 & (TT2012, 2012) \\
$\varepsilon_{\mathrm{p}}$ & Trip rate annual growth & variable & & - \\
$\rho_{\mathrm{N} 0}$ & Proportion of population that are non-drivers (\%) & 17.1 & 2017 & (Statistics Canada, 2019) \\
$k_{\mathrm{n}}$ & Inflection for increase in new users & 0.5 & - & Typical s-curve \\
$k_{\mathrm{e}}$ & Inflection for increase in e-commerce & 0.5 & - & Typical s-curve \\
$\rho_{0 \mathrm{~s}}$ & Base year e-commerce proportion (\%) & 9 & 2017 & (Rigby, 2011) \\
$\Delta \rho_{0 \mathrm{~s}}$ & Horizon year difference from the base year e-commerce (\%) & $11 \%$ & 2011 & (Rigby, 2011) \\
$A_{\mathrm{r} 0}$ & Land used for SED in 2006 (million square-meters) & 13.462 & 2006 & (Buliung \& Hernández, 2009) \\
\hline
\end{tabular}

\subsection{Trip Rates}

The literature reviewed above suggests that CAV cost reduction will increase the propensity to travel for discretionary purposes. The convenience of door-to-door travel will provide greater accessibility for the non-driver population and increase trip production. These changes will occur gradually over time as users adopt CAVs. A summary of multiple studies estimated that CAVs would reduce the cost per kilometer from today's private vehicles by $45 \%$ to $82 \%$ (Audenhove, et al., 2018). Based on the price elasticity of the Uber study (Cohen, et al., 2016), this cost reduction could result in an increase in future trip rates by the same proportion. Therefore, the analysis will include a range of future trip rate increases from zero to $100 \%$ to cover the potential future scenarios.

\subsection{Land Use}

A comprehensive study of land use in the GTA found that in 2006 there were 144.9 million squarefeet (13.5 million square-meters) of land used for SED (Buliung \& Hernández, 2009). The facilities comprised of shopping centers, power centers, and strips. The land use distributed across various center types including super, regional, community, neighborhood, convenience, and freestanding. The 2011 Canadian survey "Transportation Tomorrow" reported that in 2006, there were 12,244,700 daily trips of which $40 \%$ were discretionary (TT2012, 2012). This equated to an average of 
approximately 133 annual trips per square-meter of SED land area in the GTA. The model development uses this metric as a minimum threshold required to sustain business vitality in the GTA. This metric is likely to be different for other metropolitan areas.

For the analysis base year, the GTA population was 6.9 million (MOF, 2018). The average daily trips per person, excluding those younger than 11 years old, remained at 2.4 from 1986 to 2011. Hence, the model parameter estimation uses the same rate of annual trips for the base year. Sensitivity analysis for the horizon year establishes the average daily trips per person as a variable. The proportion of trips made by car in the base year was $78 \%$. The sensitivity analysis for the horizon year used car proportion as a variable and used a range of values below and above the base year proportion.

\subsection{E-commerce Adjustment}

According to the U.S. Census Bureau, online shopping accounted for $9.1 \%$ of sales in the analysis base year (U.S. Census Bureau, 2019). It is difficult to measure e-commerce because many online purchases result after visiting a store to evaluate an item. Conversely, digital information influences a significant portion of in-store sales. There is also a bias towards a few dominant online retailers that heavily drive e-commerce sales. Discretionary trips made for dining and entertainment may include other forms of shopping. Consequently, analysts forecast that the e-commerce proportion will plateau at $20 \%$ in the horizon year (Rigby, 2011). Model parameter estimation uses this proportion as a peak in the avoidance of shopping trips.

\subsection{New Users}

Historically, the annual population growth rate from 1974 to 2014 ranged from $1.5 \%$ to $2.6 \%$ with an average of $1.9 \%$ (Wang, et al., 2015). This growth rate correlated with a mean annual urban expansion rate of $1.6 \%$. The Ministry of Finance forecast of $1.43 \%$ mentioned earlier reflects a slight saturation due to further urbanization and sprawl (Figure 1).

According to Statistics Canada, the country had 6.25 million adults with disabilities in 2017 (Statistics Canada, 2019). This amount is equivalent to $17.1 \%$ of the population and does not include other non-drivers such as people younger than 15 years, the institutionalized population, and those living in collective dwellings. Other non-drivers who are not disabled include the elderly. For a conservative estimate, the model parameter estimation uses the base year disabled population proportion as the maximum level of new users in the horizon year.

\section{RESULTS}

The next two sections evaluate the model to reveal annual trends for important variables that CAVs could influence, and the demand sensitivity to those variables in the horizon year. The variables simulated are a mode shift towards using cars for shopping, and a change in the propensity to travel because of door-to-door convenience and a reduction in the value of time. The latter will affect the average number of daily trips per person.

\subsection{Annual Trend}

Figure 2 plots the change in demand for SED land use relative to the base year for three scenarios of trip rate elasticity while keeping the proportion of cars unchanged from the base year. The model shows that the demand is non-linear over time, which the straight line (Linear Ref) makes easier to observe. With no change in trip rate (No CAV), the demand for SED land use in the horizon year 
1 increases by $59.2 \%$ from the base year, reflecting the effect of population growth alone. If CAV use 2 results in a $50 \%$ increase in trip rate (CAVmin), then the demand increases by a factor of 2.24, 3 which is a $40.6 \%$ increase from the demand by population growth alone. If CAV use results in a $100 \%$ increase in trip rate (CAVmax), then the incremental increase in demand is $84.7 \%$. If CAV use results in a further change in the proportion of trips by car to $90 \%$, then the additional increase in demand is nearly 100\% (not shown on the graph). These results suggest that CAVs have the potential to double the demand for SED land use over that from population growth alone.

Figure 3a includes a range of proportion of trips by car from $50 \%$ to $100 \%$ and plots the proportional change in horizon year demand relative to a forecast that maintains the base year values for those factors (Table 1). The "No CAV" scenario simulates zero elasticity in average daily trip rate from CAV adoption by maintaining the base year rate. With no elasticity in trip rate, a change in trip proportion by car from $50 \%$ to $100 \%$ of the base year value results in a reduction of $4.2 \%$ to an increase of $3.3 \%$ in demand for SED land use, respectively. If elasticity from CAVs increases trip rate by $2.2 \%$ annually to result in double the trip rate in the horizon year (CAVmax), the same range in proportion of trips by car results in a 50\% increase to a doubling of demand for SED land use, respectively. If elasticity increases trip rate by $1.2 \%$ annually to result in a $50 \%$ increase in the horizon year trip rate (CAVmin), the change in demand for SED land use is midway between the two trip rate extremes. This result demonstrates that the average daily trip rate per person modulates the demand sensitivity to the proportion of trips by car.

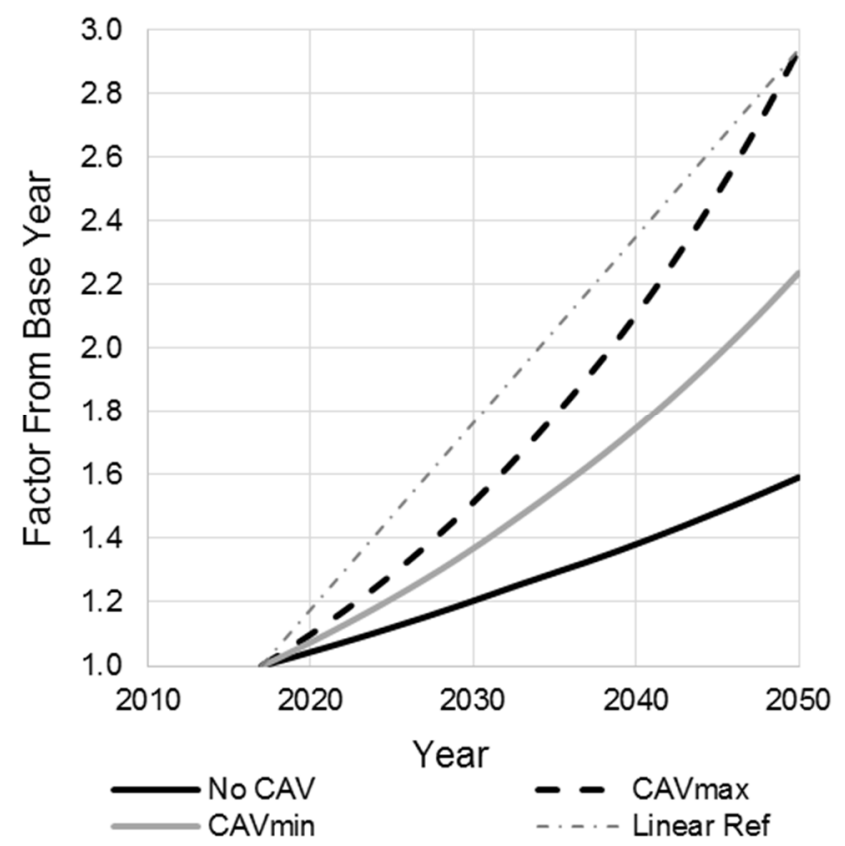

Figure 2. Relative demand as a function of time for scenarios of trip rate and proportion of trips by car.

\subsection{Horizon Year Sensitivity}

Figure 3 shows the sensitivity of demand for SED land use in the horizon year to the proportion of trips by car and the average daily trip rate per person. Figure $3 b$ shows the demand sensitivity for SED land use with trip rate, for three scenarios of proportion of trips by car. If the proportion of cars 
1 used for SED trips in the horizon year is half that of the base year, then demand for SED land use will range from a 5.9\% reduction to a $36.5 \%$ increase from the horizon year nominal, respectively. For a 100\% car use proportion, the range goes from a 3.3\% increase to a doubling in demand for SED land use. This result demonstrates that the proportion of trips by car modulates the demand sensitivity to the average daily trip rate per person.

ه)

a) 2.3

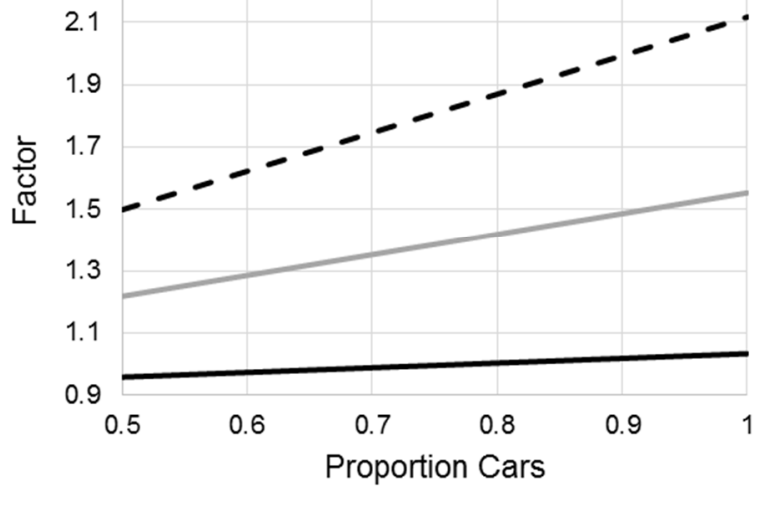

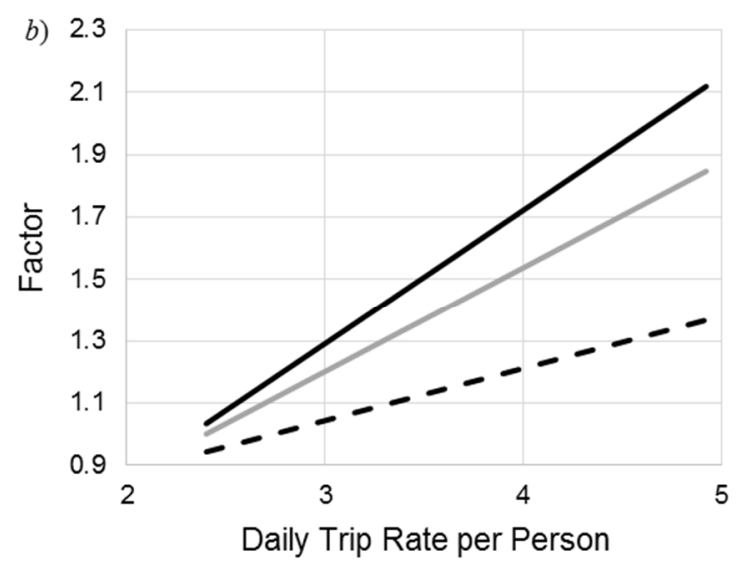

Figure 3. a) Demand sensitivity as a function of the proportion of trips by car for three scenarios of trip rate, and b) demand sensitivity as a function of trip rate for three scenarios of proportion of trips by car.

12

\section{DISCUSSION}

The model provides a first-order macroscopic view of the possible extent that CAVs might affect the overall demand for SED land use in a region. More complex geospatial models are necessary to characterize local and microscopic effects. For example, some areas may have more land available and higher capacity roadways to accommodate the projected increase in SED land use. Land price may increase in regions that have less available land and less roadway capacity, which could stimulate urban sprawl or the development of SED areas away from the central business district. The closed-form model complements data-driven models that are more complex by enabling rapid sensitivity analysis for a larger range of scenario variations. Sensitivity analysis reveals important trends and provides insights on the importance level of various factors in adoption. The interactions of different forecasting models in the closed-form expression provide additional insights that a more complex data-driven model might not.

The model is based on the theory that a certain number of trips per unit of SED land use is necessary to sustain the viability of those businesses. The model uses the metric available for 2006 and assumes that it remains unchanged for the GTA, which is one of the largest metropolitan areas in North America. However, the high land value, on-going rapid transformations of the city, and political pressures against urban sprawl may change the metric for SED business viability in the region. For example, the metric could change if large-scale businesses overpower small businesses by centralizing in super-centers at the metropolitan fringes to reduce cost and increase the efficiency of their supply chains. Consequently, a change in the metric could affect the sensitivity of demand to variables that CAVs influence. 
Differences in the level of CAV adoption over time and other factors such as a fear of riding in a vehicle driven by artificial intelligence could affect the propensity to travel. Factors other than cost, convenience, and the value of time may affect the propensity to travel for discretionary trips. Such factors could include social interaction, multi-purpose trips, the level of congestion, and weather conditions. Given the uncertainties of how CAVs will affect travel behavior, an effective strategy is to evaluate demand sensitivity to variables that CAVs can affect for a range of possible values to identify trends. Such an evaluation would take much longer to accomplish with a datadriven model.

Changes in accessibility for the non-driver population depend on the level of CAV adoption. The model simulates this interaction by using a theory of technology diffusion that simulates initial use by first adopters, then ramping adoption to include early adopters, early majority, late majority, and eventually a plateauing towards full adoption in the horizon year when laggards follow. The proportion of people considered non-driver will vary across regions, and the proportion of that population using CAVs will vary. A survey of the region could reveal those proportions to estimate model parameters.

Shopping trip erosion depends on the saturation year for e-commerce, the interaction effects from future automated vehicle and drone delivery services, and the reality of how store visits drive online purchases and vice versa. Hence, the model uses predictions in the literature to estimate the level of e-commerce saturation in the horizon year. The estimation is a proportion of all discretionary trips. As discussed in the model development, it is possible to separately model land use demand for retail, entertainment, and dining trips to more accurately account for the e-commerce effect. Nevertheless, the results show that the on-line shopping effect is not sufficiently dominant to temper the demand for SED land use, which has been trending towards mixed-use spaces (Raman \& Roy, 2019).

Without accounting for other CAV deployment effects, it may seem unrealistic that cities could accommodate the increase in traffic that results from a tripling of the demand for SED land use over the demand from population growth alone. However, the practicality becomes clear when considering that studies expect CAVs to increase both traffic throughput and transport efficiency (Raymond, et al., 2014). For instance, a shift from private car ownership toward the use of shared CAVs will result in fewer vehicles moving more people. The effective capacity of existing roadways will increase because CAVs will have the ability to follow more closely, smooth out traffic flows, coordinate traffic flows through intersections, and minimize incidents that can cause non-recurring congestion. CAVs will also accommodate geometric modifications to add lanes. Specifically, cities can repurpose street parking where demand lessens and narrow lanes, medians, and shoulders where only CAVs travel. All scenarios are predicated on the theory that suppliers of the technology will continuously pursue market opportunities that balance supply and demand through the adoption period.

\section{CONCLUSIONS}

Population growth alone will drive demand for more shopping, entertainment, or dining (SED) land use. However, the literature lacks studies about how CAV adoption might influence that demand. Uncertainties about the timing of CAV deployments and their levels of adoption result in speculations based on various assumptions. Traditional methods to model travel demand require vast amounts of data that could be expensive to obtain. Such methods use expensive software and require trained professionals to configure and calibrate them. Using such models to explore a single future 
scenario can take hours. Alternative closed-form models to quickly assess the potential aggregate effect that CAVs may have on the regional demand for SED land use does not exist.

This work contributes a closed-form model that enables demand forecast and sensitivity analysis for a range of factors that CAV adoption could affect. The sensitivity analysis focused on two important factors, namely the average daily trip rate per person and the proportion of trips taken by car. A change in the average daily trip rate stems from the notion that CAVs will increase the propensity to travel because of future cost reduction, on-demand door-to-door convenience, reduction in the value of time, and more reliable travel time from smoother traffic flows and fewer incidents. For the same reasons, CAV adoption will also influence a mode shift toward cars. Regional data for the population size, SED land use, proportion of non-drivers, proportion of trips taken by car, average trip rate per person, and the proportion of shopping done by e-commerce estimates model parameters for the base year. Forecasts for population growth and SED trip avoidance from e-commerce appropriately adjust the trip demand over time. The model accounts for additional trips taken by the non-driver population based on an estimate for the technology diffusion rate.

The authors selected the Greater Toronto Area (GTA) for modeling because of familiarity with the area and knowledge of data sources that are unique to the region. The results revealed that population growth alone could increase the demand for SED land use by nearly $60 \%$ from the base year of 2017 to the horizon year of 2050. For a scenario where CAVs influence a $100 \%$ increase in the average trip rate per person from 2.7 to 5.4 and increases the use of cars from $78 \%$ to $90 \%$, the demand for SED land use could triple by the horizon year. For a scenario where CAV use results in a more modest increase in the average trip rate per person by $50 \%$, without a change in the proportion of cars used for shopping, the demand more than doubles from the base year. Sensitivity analysis for the horizon year shows that the potential change in demand for SED land use is a strong function of the influence CAVs could have on both the propensity to travel for discretionary purposes and a mode shift towards cars.

In future research, the authors will apply traditional travel demand modeling techniques and use a similar range of scenarios to compare results with the closed-form model.

\section{REFERENCES}

Anderson, J. M. et al., 2014. Autonomous vehicle technology: A guide for policymakers. s.1.:Rand Corporation.

Arabani, M. \& Amani, B., 2007. Evaluating the parameters affecting urban trip-generation. Iranian Journal of Science and Technology, 31(B5), p. 547.

Arentze, T. A., Oppewal, H. \& Timmermans, H. J., 2005. A multipurpose shopping trip model to assess retail agglomeration effects. Journal of Marketing Research, 42(1), pp. 109-115.

Audenhove, F.-J.V. et al., 2018. The Future of Mobility 3.0: Reinventing mobility in the era of disruption and creativity, s.1.: Arthur D. Little.

Bagloee, S. A., Tavana, M., Asadi, M. \& Oliver, T., 2016. Autonomous vehicles: challenges, opportunities, and future implications for transportation policies. Journal of Modern Transportation, 24(4), pp. 284-303.

42

Banai, R. \& Antipova, A., 2016. Retail-center viability and urban form: a micro analysis. The

43 International Review of Retail, Distribution and Consumer Research, 26(5), pp. 521-540. 
1 Bansal, P. \& Kockelman, K. M., 2017. Forecasting Americans' long-term adoption of connected and autonomous vehicle technologies. Transportation Research Part A: Policy and Practice, Volume 95, pp. 49-63.

Bösch, P. M., Becker, F., Becker, H. \& Axhausen, K. W., 2018. Cost-based analysis of autonomous mobility services. Transport Policy, Volume 64, pp. 76-91.

Buliung, R. \& Hernández, T., 2009. Places to Shop and Places to Grow: Power Retail, Consumer Travel Behaviour, and Urban Growth Management in the Greater Toronto Area, s.1.: Neptis Foundation.

Calvert, S. et al., 2018. Traffic flow of connected and automated vehicles: Challenges and opportunities. In: Road Vehicle Automation 4. Cham: Springer.

Cohen, P. et al., 2016. Using big data to estimate consumer surplus: The case of Uber, s.1.: National Bureau of Economic Research.

Daamen, W., Hoogendoorn, S. P. \& Bovy, P. H., 2005. First-order pedestrian traffic flow theory. Transportation research record, 1934(1), pp. 43-52.

Dedon, L. et al., 2018. State Strategies to Reduce Highway and Traffic Fatalities and Injuries: A Road Map for States, s.1.: s.n.

Henderson, J. \& Spencer, J., 2016. Autonomous vehicles and commercial real estate, s.1.: Cornell Real Estate Review.

Hussain, R., Lee, J. \& Zeadally, S., 2018. Autonomous Cars: Social and Economic Implications. IT Professional, 20(6), pp. 70-77.

Kempton, W., 2016. Electric vehicles: Driving range. Nature Energy, 1(9), p. 16131.

Lam, C. T. \& Liu, M., 2017. Demand and consumer surplus in the on-demand economy: the case of ride sharing. Social Science Electronic Publishing, 17(8), pp. 376-388.

Lee, R., Sener, I., Mokhtarian, P. \& Handy, S., 2017. Relationships between the online and in-store shopping frequency of Davis, California residents. Transportation Research Part A: Policy and Practice, Volume 100, pp. 40-52.

Litman, T., 2017. Autonomous vehicle implementation predictions, Victoria, Canada: Victoria Transport Policy Institute.

Lyons, G., 2006. The role of information in decision-making with regard to travel. s.1., IET Digital Library, 2006., pp. 199-212.

Maat, K. \& Konings, R., 2018. Accessibility or innovation? Store shopping trips versus online shopping. Transportation Research Record, 2672(50), pp. 1-10.

Melis, K., Campo, K., Breugelmans, E. \& Lamey, L., 2015. The impact of the multi-channel retail mix on online store choice: does online experience matter?. Journal of Retailing, 91(2), pp. 272-288. MOF, 2018. Ontario Population Projections Update, 2017-2041, Ontario: Ministry of Finance (MOF).

Oum, T. H., Waters, W. G. \& Yong, J. S., 1990. A survey of recent estimates of price elasticities of demand for transport, Washington, DC: World Bank. 
1 Pollard, J. H., 1973. Mathematical models for the growth of human populations. Cambridge:

2 Cambridge University Press.

3 Raman, R. \& Roy, U. K., 2019. Taxonomy of urban mixed land use planning. Land Use Policy,

4 Volume 88, p. 104102.

5 Raymond, H., Arerm, B. v. \& Hoogendoom, S., 2014. Automated driving, traffic flow efficiency,

6 and human factors: Literature review. Transportation Research Record, 2422(1), pp. 113-120.

7 Rigby, D. K., 2011. The Future of Shopping. Harvard Business Review, December.

8 Rogers Everett, M., 2003. Diffusion of innovations. 5th ed. New York: Free Press.

9 Shenstone-Harris, S., 2016. Have we reached peak driving?: A 25-year decomposition of vehicle

10 trends in Canada, s.l.: University of Ottawa.

11 Sivak, M. \& Schoettle, B., 2015. Influence of current nondrivers on the amount of travel and trip 12 patterns with self-driving vehicles, Ann Arbor, Michigan: The University of Michigan Transport

13 Research Institute.

14 Soteropoulos, A., Berger, M. \& Ciari, F., 2019. Impacts of automated vehicles on travel behaviour 15 and land use: an international review of modelling studies. Transport reviews, 39(1), pp. 29-49.

16 Statistics Canada, 2019. Canadian Survey on Disability Reports. [Online]

17 Available at: https://www150.statcan.gc.ca/n1/en/catalogue/89-654-X

18 [Accessed 24 May 2019].

19 TT2012, 2012. Transportation Tomorrow: Travel Survey Summaries for the Greater Toronto and 20 Hamilton Area, Toronto: University of Toronto.

21 Tussyadiah, I. P., Zach, F. J. \& Wang, J., 2017. Attitudes toward autonomous on demand mobility

22 system: The case of self-driving taxi. Cham, Springer, pp. 755-766.

23 U.S. Census Bureau, 2019. US E-Commerce Sales as Percent of Retail Sales. [Online]

24 Available at: https://ycharts.com/indicators/ecommerce_sales_as_percent_retail_sales

25 [Accessed 24 May 2019].

Wang, L., Li, W., Wang, S. \& Li, J., 2015. Examining Urban Expansion in the Greater Toronto Area Using Landsat Imagery from 1974-2014. GEOMATICA, 69(2), pp. 161-172..

Wang, W., Song, Y., Zhang, J. \& Deng, H., 2014. Automatic parking of vehicles: A review of literatures. International Journal of Automotive Technology, 15(6), pp. 967-978.

Webber, S. \& Hernandez, T., 2016. Big box battles: the Ontario Municipal Board and large-format retail land-use planning conflicts in the Greater Toronto Area. International Planning Studies, 21(2), pp. 117-131.

Zhao, Y. \& Kockelman, K. M., 2018. Anticipating the regional impacts of connected and automated vehicle travel in Austin, Texas. Journal of Urban Planning and Development, 144(4), p. 04018032. 